\title{
Design of Comprehensive Photo-thermal Utilization System for Vocational Training
}

\author{
Jia Zhang, Qingji Xu \\ Department of New Energy Engineering, Tianjin Sino-German University of Applied Sciences, YaShen Road \\ NO.2, HaiHe Education Park, Tianjin, China \\ hdzj18@126.com
}

Keywords: photo-thermal system, solar energy, floor heating system, controller, vocational education

\begin{abstract}
The existing photo thermal training equipment in vocational education is usual a simulative system that cannot support practical training exercises. As well as, different photo-thermal technologies cannot comprehensively integrated for study. To solve these defects, this paper puts forward a comprehensive photo-thermal training system. This system combines traditional solar energy application system and radiant floor heating system together with an independent-design controller. Through this system, different photo-thermal technologies are integrated for practical training and the processes of signal collection and control are optimized. Therefore, this new system will perfect recent vocational education equipment and provide technique supporting for relative research.
\end{abstract}

\section{Introduction}

Photo-thermal technology is a kind of clean and renewable energy technology, which is more and more popular in current research and education fields. In China, this technology plays an important role in new energy field of vocational education. The recent researches about photo thermal are mainly focus on the system design [1], power generation [2], heat collection, domestic hot water supporting [3][4]. The existing photo thermal equipment in vocational education is usual a simulative system that cannot support practical training practices. As well as, different photo-thermal technologies cannot comprehensively integrated for study. To solve these defects, this paper puts forward a comprehensive photo-thermal system of domestic hot water supplying.

\section{System Compositions and Design Theories}

\subsection{System Compositions}

This comprehensive system mainly contains: solar thermal collector, circulating water pump, water tank, thermal meter, electric heater, vent-pipe, manual valve, water supplement solenoid valve, liquid level sensor, temperature and humidity sensor, floor heating equipment, I/O controller, AC contactor, AC circuit breaker, adapter, touch screen, M-BUS to RS485 conversion module and indicator lights.

\subsection{Water-cycling System Design}

The whole photo-thermal water-cycling system is designed as following drawing: 


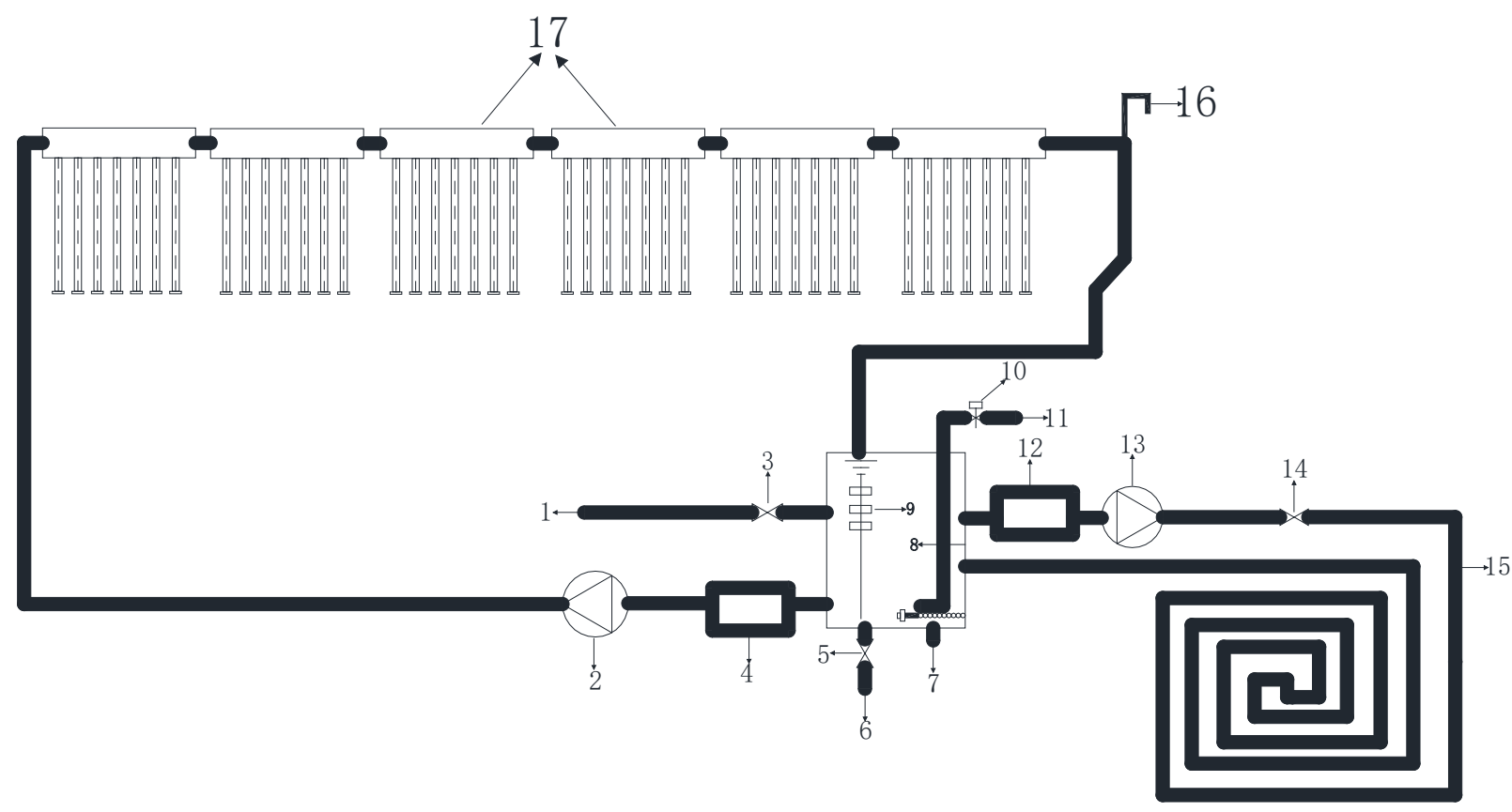

Figure 1. Structure drawing of photo-thermal water-cycling system

Table 1. Photo-thermal water-cycling system components

\begin{tabular}{|l|l|l|l|l|l|}
\hline 1 & 2 & 3 & 4 & 5 & 6 \\
\hline $\begin{array}{l}\text { Domestic } \\
\text { water pipe }\end{array}$ & $\begin{array}{l}\text { Circulating } \\
\text { pump 1 }\end{array}$ & $\begin{array}{l}\text { Manual } \\
\text { valve 1 }\end{array}$ & Heat meter 1 & $\begin{array}{l}\text { Manual } \\
\text { valve 3 }\end{array}$ & $\begin{array}{l}\text { Sewage } \\
\text { pipe }\end{array}$ \\
\hline 7 & 8 & 9 & 10 & 11 & 12 \\
\hline $\begin{array}{l}\text { Electric } \\
\text { heater }\end{array}$ & Water tank & $\begin{array}{l}\text { Liquid } \\
\text { level } \\
\text { sensor }\end{array}$ & $\begin{array}{l}\text { Water } \\
\text { supplement } \\
\text { solenoid } \\
\text { valve }\end{array}$ & $\begin{array}{l}\text { Cold water } \\
\text { inlet }\end{array}$ & $\begin{array}{l}\text { Heat } \\
\text { meter 2 }\end{array}$ \\
\hline 13 & 14 & 15 & 16 & 17 & \\
\hline $\begin{array}{l}\text { Circulating } \\
\text { pump 2 }\end{array}$ & $\begin{array}{l}\text { Manual valve } \\
2\end{array}$ & $\begin{array}{l}\text { Radiant } \\
\text { floor } \\
\text { heating }\end{array}$ & Vent pipe & $\begin{array}{l}\text { Solar } \\
\text { thermal } \\
\text { collector }\end{array}$ & \\
\hline
\end{tabular}

As the designed system in figure 1, circulating water is heated in solar thermal collector and then flows into the tank. One part of the heated water supplies the daily used water in bathroom and the other part of heated water flows into the floor heating system. Circulating water pump provides enough circulating pressure to the two hot water recycling systems. Thermal meter 1 and thermal meter 2 real-time measure and collect the temperature, flow rate and heat amount of the two recycling systems separately. Liquid level sensor and electric heater are installed in the water tank, the liquid level sensor real-time measures the water lever changes and reports to the control system to supplement cold water to the tank through adjusting water supplement solenoid valve. A temperature and humidity sensor is installed in the room, this sensor monitors temperature and humidity changes in this room. The electric heater in water tank will work when the room temperature is not high enough. 


\subsection{Control System Design}

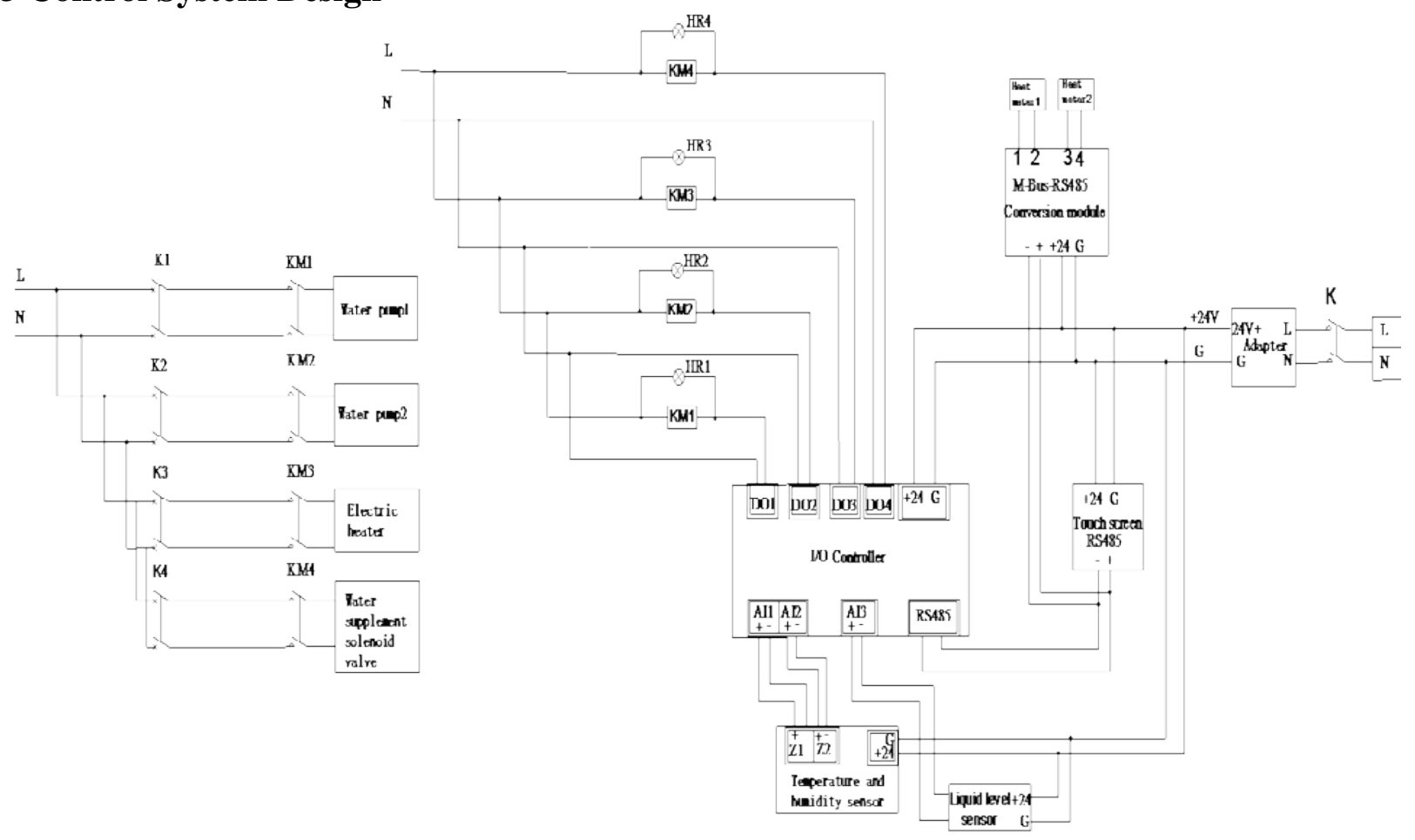

Figure 2. Electric drawing of the control system

An independent-design controller is applied in this photo-thermal system. This I/O controller collects temperature and humidity of floor heating room and also collects the liquid level of tank in real time. Based on the collected data, this controller will judge if the solenoid valve, electric heater and circulating water pump 2 should be opened. Furthermore, thermal meter is able to communicate with I/O controller and touch screen through RS485 Bus [5]. And the collected real-time data will display on the screen and stored in hard drive automatically. The controller will executive commands from touch screen to trigger AC contactor coil through DO PIN. Then the on-off state of contactor could be controlled [6]. (The electric drawing of control system for this photo-thermal training system is shown in figure 2.)

An adapter is designed to supply DC power to this photo-thermal system by converting AC220V to DC $24 \mathrm{~V}$. The AC220V power supply is also used in the AC contactor.

Figure 2 is the electric control drawing of this photo-thermal system. In this figure, K1, K2, K3, K4 are the manual AC breakers and KM1、KM2、KM3、KM4 are AC contactors coils. Commands from touch screen can trigger KM1、KM2、KM3、KM4 though terminals DO1、DO2、DO3、 DO4, then pump 1, pump 2, electric heater and water supplement solenoid valve can be controlled separately. The on-off state of KM1 KM2、KM3、KM4 is indicated by four lights HR1-4 and all contactors are powered and controlled by AC220V sources. The terminals AI1, AI2 of I/O controller are connected with temperature and humidity sensor, and this sensor is used to collect temperature data and is powered by DC24V. Liquid sensor is connected with AI3 and powered by DC24V. All data collected by thermal meter will be displayed on touch screen and stored through M-BUS, and M-BUS should transfer into RS485 Bus. The communication mode between touch screen, I/O controller and conversion module is RS485. The DC24V power source is transferred from AC220V, and the manual AC breaker "K" controls the whole control system. Besides, in "Auto" mode, I/O controller can control the on-off state of water supplement solenoid valve, electric heater and water-cycling pump by measuring the water temperature in tank and the humidity and temperature of the room. When the water level in the tank is low, solenoid valve will be turned on to feed cold water. The electric heater will work when the room temperature is low and the water-cycling pump 2 will be stopped if the room temperature is too high. Water-cycling pump 1 works in normal operation. 


\section{Conclusion}

This photo-thermal system reflects the comprehensive application of new energies, which can supply a whole-year hot water for daily life and can also replace traditional heating system with low cost. The self-designed control system is highly efficient and the whole system is clearly to understand. All the units in this system can be assembled and match flexible to improve practical skills of students. This system can carry out the following experiments: solar energy collection and conversion theories, photo-thermal collection pipe characteristics testing [7], outside environment effects of photo-thermal conversion, solar water heater functions, inner connection of solar hot water system, flat plate heat collector working theories and low temperature floor radiant heating system testing. Therefore, this system can match the study and training requirements of teachers and students.

\section{Acknowledgements}

This research was supported by the Tianjin Education Science "The 13th Five-year" Program Project "Research on the cultivation of systematic talents of the energy specialty" (Project No. VEYP5040). And the Science and Technology Program Project of Jin Nan District Tianjin.

\section{References}

[1] L.Zhang and Y.F.Zhang, Research on Heat Recovery Technology for Reducing the Energy Consumption of Dedicated Ventilation Systems: An Application to the Operating Model of a Laboratory, Energies, 24,9,(2016)

[2] G. Wang, XU. Shuyun, Review on the Major Techniques and Applications of Photo-thermal Utilization of Solar Energy, Materials Review, (2014)

[3] JC. Evarts and LG. Swan, Domestic hot water consumption estimates for solar thermal system sizing, Energy \& Buildings, 58-56,58(2), 2013

[4] Z. Chen, L. Zhang, J. Zhang, Design and analysis of the movable solar energy heat utilization system, International Conference on Advanced Electronic Science and Technology, 2016

[5] YH, Shi, M. Gao, TX. Li, The application of RS485 Bus in the Intelligent Power Supply System, Control \& Automation, 179-180,23(5), 2007

[6] RA. Gupta, MY. Chow, Networked Control System: Overview and Research Trends, IEEE Transactions on Industrial Electronics, 2527-2535, 57(7), 2010

[7] L. Zhang, W.L. Lee, Evaluating the use heat pipe for dedicated ventilation of office buildings in Hong Kong, Energy Conversion and Management, 1983-1989, 52, 2011 